\title{
Changing Epidemiology of Human Mycoses-China and Beyond
}

\author{
S. S. Y. Wong $\cdot$ K. Y. Yuen
}

Received: 6 April 2011/Accepted: 6 April 2011/Published online: 20 April 2011

(C) Springer Science+Business Media B.V. 2011

Emerging and reemerging infectious diseases have shaped the landscape of medicine for the past three decades. Viral pathogens, especially those zoonotic in origin, have been in the centre of the limelight. It has been estimated that viruses and prions accounted for $43 \%$ of the 177 emerging and reemerging human pathogens up to 2005 [1]. Fungi are the minority this regard, as they made up only $12 \%$ of the pathogens in that survey.

Mycoses are frequently neglected as emerging and reemerging diseases. They do not normally cause explosive outbreaks, nor do they give rise to pandemics. Nevertheless, changes in the epidemiology of human mycoses have been taking place over the past decades, both in terms of the absolute numbers of patients affected and the diversity of pathogens involved. In this issue of Mycopathologia, $\mathrm{Wu}$ et al. described the epidemiology of human pathogenic fungi in China through three 10-yearly surveys $(1986,1996,2006)$ in 39 centres in China (including Taiwan) [2]. The key findings of the study include a decline in the number and proportion of dermatophytes among all the clinical isolates, and a rising prevalence of yeasts and other moulds being

S. S. Y. Wong · K. Y. Yuen $(\bowtie)$

Department of Microbiology, Research Centre

of Infection and Immunology, The University

of Hong Kong, Hong Kong, China

e-mail: kyyuen@hku.hk recovered. The diversity of the species of fungi isolated also increased throughout the years.

A few considerations need to be taken in the interpretation of the data. While the change in the number of isolates could well be genuine, the population change during the study period has to be taken into account. The total population of China increased by almost 23\% (an increase of over 244 million people) from 1986 to 2006 [3]. At the same time, the birth control policy of China results in a gradual change in the age structure of the population; in $1986,70 \%$ of the population were aged 15 years and above, the figure rose to $79 \%$ in 2006 [3]. We are not totally certain whether the increase in numbers translate into increase in incidence of the infections. Secondly, does the increase in the number of species recovered represent improvements in fungal culture and identification techniques? For example, the two key examples of fluconazole-resistant Candida species, C. krusei and C. glabrata, were not represented at all in the 1986 data set. Thirdly, although it was commented that 'all the strains were cultured from patients with clinically proven or suspected fungal infections', the standard criteria for taking clinical samples and the nature of clinical specimens from which the fungi were isolated was not detailed in the article, and it would, therefore, be difficult to judge whether all the isolates represent genuine pathogens, co-pathogens or colonizers. Fourthly, could the changing prevalence of certain pathogens be due to changes in clinical practice and sampling? For 
example, one of the most notable findings is the dramatic decrease in the number and proportion of dermatophytes isolated. This could well be due to improved efforts in the control of the infection in the community. On the other hand, with the wider availability of over-the-counter topical antifungals and better primary care, many of the patients may be self-treated at home or in clinics where clinical specimens will not be collected for mycological studies.

Despite the limitations of the study, it still provided some useful insights into the various facets of mycoses in China. The opening of China in 1976 has led to marked socioeconomic improvement. The associated improvement in living condition and personal hygiene will definitely impact on the incidence of dermatophytosis. The increase in the prevalence of Microsporum canis among the dermatophytes could well be explained by the rising pet ownership in China as pointed out by the authors. The improving socioeconomic conditions and better access to medical care are associated with longer life span and a growing population of immunosuppressed hosts. The growing importance of Candida spp. and Cryptococcus neoformans is most likely accountable by the increasing population of hospitalized patients and immunocompromised patients. Antibiotic misuse and overprescription in China has been a major problem, and the situation is not just limited to hospitals but also to the communities where over-the-counter antibiotics are readily available [4]. In addition to $C$. neoformans, the dimorphic fungus Penicillium marneffei is another major opportunistic fungal pathogen among AIDS patients in Southeast Asia including southern China [5]. The first AIDS patient was diagnosed in China in 1985, and by 1998 all provinces of China reported HIV/AIDS [6]. However, the official surveys for HIV/AIDS in China did not appear until 2003 [7]. It is conceivable that the growing AIDS epidemic must have contributed significantly to the changing epidemiology of human mycoses in China in the past 25 years.

Woolhouse and Gowtage-Sequeria suggested that the two major driving forces for emerging and reemerging fungal diseases are hospitals and medical procedures and poor population health (including various immunocompromising conditions) [1]. The former is well exemplified by the increasing incidence of invasive candidiasis among hospitalized patients, especially in those who had received multiple broad spectrum antibacterials. The latter is best represented by the AIDS pandemic since the 1980s. Indeed, Pneumocystis jiroveci-then generally considered to be a protozoan parasite-was the earliest emerging mycosis that led to the recognition of HIV/AIDS [8]. Similar to $P$. jiroveci, it took more than 90 years since the initial isolation of Cryptococcus neoformans before its clinical importance was re-appreciated after the AIDS pandemic. P. marneffei, previously unknown to most western microbiologists, was rediscovered after the AIDS pandemic spread to Southeast Asia in the late 1980s [5].

The AIDS pandemic is but one contributing factor to the emergence or reemergence of fungal infections globally. Advances in treatment of malignancies and autoimmune diseases, solid organ and haematological stem cell transplantation and development of new immunosuppressants have created an increasing population of immunocompromised patients. Invasive aspergillosis and infections due to other hyaline moulds have caused the greatest proportion of mortality due to mycoses in this group of highly susceptible hosts. Invasive aspergillosis, the commonest of all these mould infections, has driven the development of several new antifungal agents (e.g. voriconazole, posaconazole, the echinocandins), and nowadays, there is a larger armamentarium for the treatment of this disease [9]. However, infections caused by a number of moulds remain extremely difficult to manage, such as Fusarium spp. and the Zygomycetes.

Prolonged prophylaxis or treatment with antifungals has reduced the incidence of a number of invasive fungal infections. Unfortunately, such strategies in some situations have iatrogenically driven the emergence of new fungal pathogens. The widespread use of fluconazole prophylaxis for neutropenic patients and haematological stem cell transplant recipients have resulted in increasing incidence of infections due to fluconazole-resistant Candida spp. (such as C. glabrata and C. krusei) in some centres $[10,11]$. In recent years, voriconazole prophylaxis has finally brought hope to the prevention of invasive aspergillosis in high-risk patients. Unfortunately, this has resulted in the emergence of invasive zygomycosis in some centres, which is even more difficult to treat than aspergillosis $[12,13]$. 
Selection of highly resistant fungi by new antifungals is not the only example of a man-made evolution in the epidemiology of fungal infections. Other human factors have contributed to outbreaks of serious mycoses. Fusarium keratitis have been associated with the use and improper care of contact lenses [14, 15]. In 2005, a multinational outbreak of Fusarium keratitis was found to be related to the use of a new formulation of contact lens solution (not, however, related to contamination of the solution) [16, 17]. The solution was finally withdrawn from the market globally in 2006. In 2009, an unusual outbreak of intestinal mucormycosis due to Rhizopus microsporus occurred among patients with haematological malignancies in a tertiary care hospital, leading to infection of 12 patients and 5 of them died [18]. The source of $R$. microsporus was traced to contaminated generic allopurinol tablets manufactured in a local pharmaceutical plant.

Cryptococcus gattii represents one of the latest emerging fungal pathogens of global significance. Previously found only in tropical areas of the world, C. gattii invaded Vancouver Island, British Columbia, Canada in 1999 [19]. Since then, it has spread to British Columbia and the Pacific Northwest of the United States (Oregon, Washington, Idaho, California) [20]. The exact routes of spread to North America is still unknown, but the fungus is certainly capable of surviving and proliferating in these new ecological niches.

Fungi often do not have the dramatic nature of viruses or bacteria in terms of epidemiology. However, it is obvious that various natural and man-made factors do operate to drive the emergence and reemergence of fungal pathogens, and the consequences of their emergence is frequently global. A continued surveillance, both vertically in time, horizontally in different geographical areas and across species in both humans and animals are essential for a better understanding of their clinical and public health impacts. China is now catching up with the Western industrialized countries not only economically but also the trends in emerging fungal infections. Lessons from the past should be heeded, and there is still a long way to go in China to take on the foreseeable impact of emerging mycoses: to continue nationwide surveillance of medically important fungal pathogens, promote a culture of proper utilization of antibiotics, enforce stricter regulations on the availability of antibiotics to the general public, develop antibiotic stewardship programmes in hospitals, promulgate the proper use of antifungal prophylaxis and adopt a more open and effective control strategy for the HIV/AIDS pandemic.

\section{References}

1. Woolhouse MEJ, Gowtage-Sequeria S. Host range and emerging and re-emerging pathogens. Emerg Infect Dis. 2005;11:1842-7.

2. Wu SX, Guo NR, Liao WQ, Zhang QQ, Li CY, Li RY, Bulmer GS, Li DM, Xi LY, Lu S, Liu B, Zheng YC, Ran YP, Kuan YZ. Human pathogenic fungi in Chinaemerging trends from ongoing national survey for 1986, 1996, and 2006. Mycopathologia. 2011. doi:10.1007/ s11046-011-9398-6.

3. The World Bank. http://data.worldbank.org/indicator/ SP.POP.TOTL. Accessed 2 April 2011.

4. Reynolds L, McKee M. Factors influencing antibiotic prescribing in China: an exploratory analysis. Health Policy. 2009;90:32-6.

5. Wong SS, Yuen KY. Penicilliosis in China. Mycopathologia. 2004;158:147-50.

6. Wu Z, Wang Y, Mao Y, Sullivan SG, Juniper N, Bulterys M. The integration of multiple HIV/AIDS projects into a coordinated national programme in China. Bull World Health Organ. 2011;89:227-33.

7. Wang N, Wang L, Wu Z, Guo W, Sun X, Poundstone K, Wang Y, National Expert Group on HIV/AIDS Estimation. Estimating the number of people living with HIV/AIDS in China: 2003-09. Int J Epidemiol. 2010;39(Suppl 2):ii21-8.

8. Rogers MF, Morens DM, Stewart JA, Kaminski RM, Spira TJ, Feorino PM, Larsen SA, Francis DP, Wilson M, Kaufman L. National case-control study of Kaposi's sarcoma and Pneumocystis carinii pneumonia in homosexual men: part 2. Laboratory results. Ann Intern Med. 1983;99:151-8.

9. Boucher HW, Groll AH, Chiou CC, Walsh TJ. Newer systemic antifungal agents: pharmacokinetics, safety and efficacy. Drugs. 2004;64:1997-2020.

10. Nguyen MH, Peacock JE Jr, Morris AJ, Tanner DC, Nguyen ML, Snydman DR, Wagener MM, Rinaldi MG, $\mathrm{Yu}$ VL. The changing face of candidemia: emergence of non-Candida albicans species and antifungal resistance. Am J Med. 1996;100:617-23.

11. Horn DL, Neofytos D, Anaissie EJ, Fishman JA, Steinbach WJ, Olyaei AJ, Marr KA, Pfaller MA, Chang CH, Webster KM. Epidemiology and outcomes of candidemia in 2019 patients: data from the prospective antifungal therapy alliance registry. Clin Infect Dis. 2009;48:1695-703.

12. Kontoyiannis DP, Lionakis MS, Lewis RE, Chamilos G, Healy M, Perego C, Safdar A, Kantarjian H, Champlin R, Walsh TJ, Raad II. Zygomycosis in a tertiary-care cancer center in the era of Aspergillus-active antifungal therapy: a case-control observational study of 27 recent cases. J Infect Dis. 2005;191:1350-60.

13. Pongas GN, Lewis RE, Samonis G, Kontoyiannis DP. Voriconazole-associated zygomycosis: a significant 
consequence of evolving antifungal prophylaxis and immunosuppression practices? Clin Microbiol Infect. 2009; 15(Suppl 5):93-7.

14. Ng AS, Lau WW, Yu DK, Wong CC, Chan CW. Clinical features and outcomes of Fusarium keratitis associated with contact lens wear. Eye Contact Lens. 2008;34:113-6.

15. Gorscak JJ, Ayres BD, Bhagat N, Hammersmith KM, Rapuano CJ, Cohen EJ, Burday M, Mirani N, Jungkind D, Chu DS. An outbreak of Fusarium keratitis associated with contact lens use in the northeastern United States. Cornea. 2007;26:1187-94.

16. Ma SK, So K, Chung PH, Tsang HF, Chuang SK. A multicountry outbreak of fungal keratitis associated with a brand of contact lens solution: the Hong Kong experience. Int $\mathbf{J}$ Infect Dis. 2009; 13:443-8.

17. Chang DC, Grant GB, O'Donnell K, Wannemuehler KA, Noble-Wang J, Rao CY, Jacobson LM, Crowell CS, Sneed RS, Lewis FM, Schaffzin JK, Kainer MA, Genese CA,
Alfonso EC, Jones DB, Srinivasan A, Fridkin SK, Park BJ. Fusarium keratitis investigation team. Multistate outbreak of Fusarium keratitis associated with use of a contact lens solution. JAMA. 2006;296:953-63.

18. Cheng VC, Chan JF, Ngan AH, To KK, Leung SY, Tsoi HW, Yam WC, Tai JW, Wong SS, Tse H, Li IW, Lau SK, Woo PC, Leung AY, Lie AK, Liang RH, Que TL, Ho PL, Yuen KY. Outbreak of intestinal infection due to Rhizopus microsporus. J Clin Microbiol. 2009;47:2834-43.

19. Fyfe M, MacDougall L, Romney M, Starr M, Pearce M, Mak S, Mithani S, Kibsey P. Cryptococcus gattii infections on Vancouver Island, British Columbia, Canada: emergence of a tropical fungus in a temperate environment. Can Commun Dis Rep. 2008;34:1-12.

20. Centers for Disease Control and Prevention (CDC). Emergence of Cryptococcus gattii-Pacific Northwest, 2004-2010. MMWR Morb Mortal Wkly Rep. 2010;59: 865-8. 